\title{
Scheme Comparison of New Airport Site Selection Based on Lattice Order Decision Making Method in the Integrated Transportation System
}

\author{
http://dx.doi.org/10.3991/ijoe.v9iS4.2712 \\ Suxia Zhao ${ }^{1,2}$, Peihong Sun ${ }^{3}$ \\ ${ }^{1}$ Southwest Jiaotong University, Chengdu, China \\ ${ }^{2}$ Sichuan Vocational and Technical College of Communications, Chengdu, China \\ ${ }^{3}$ Twenty First Century Aerospace Technology Co.,Ltd. Beijing, China
}

\begin{abstract}
In view of the limited rational decision made by decision-makers in reality, multi-objective Lattice Order Decision Making is introduced in the new airport site selection and Lattice Order Decision evaluation index system is constructed. Based on the types of index, processed the index into dimensionless, Integrate decision-makers' subjective judgment and the data dispersion feature to calculate the relative weights of the evaluation index. Combined with Decision-making moment, calculate the value of comprehensive differences of the schemes, and realize the Lattice Ordering of the schemes. Apply this decision-making method to evaluate three sets of alternative airport site selection schemes in Chengdu. The outcome is consistent with the actual situation, which proved that the decision-making method is reasonable.
\end{abstract}

Index Terms-Airport Site Selection, Scheme comparison, lattice order Decision Making, Index System, Comprehensive difference value.

\section{INTRODUCTION}

According to the Civil Aviation Authority report 2008of the "national civil airport layout plan ", the number of scale and density of airport regional distribution is basically adapt to the China's regional economic and social development level, with the socioeconomic development and population growth, regional aviation supply and demand imbalance appeared and resulting in a boom of new and expansion of the airport in many regions. The construction of the airport will bring the return of the multiplier effect formula for socioeconomic development of the city, but its costly, long cycle construction and operation and inappropriate site selection will seriously affect the regional socio-economic and sustainable development of integrated transport, which is the main reason for China regional airport longterm losses.

As can be seen from t Ref. [8], in long-term, the development and construction of the negative correlation airport development and ground transportation airport must consider the impact on ground transportation. In the developed areas of ground transportation, airport cannot be blindly built and expanded. In the short term, ground transport and air transport is in a complementary relationship, airport development rely on ground transportation, the railway and highway construction should speed up within the regional airports radiation. With the deepening of our integrated transport system, the planning and layout of the airport as a transportation infrastructure should also be implemented in the context of an integrated transport system. It can be said that reasonable airport site is also a key element of the integrated transport system optimization.

After browsing a large number of references, Ref. [5] and more references focusing on the costs and benefits, or consider the cost of passenger travel and choice behavior. However, in order to establish the optimization model of decision-making, the site selection of the airport is a complex systems engineering, optimization models involving multiple areas of urban planning, social and economic, aviation network, ground integrated transportation, so the process of simplifying the problem can not cover the whole range obviously.

Addresses the above-mentioned problem, the paper incorporate the city ground transport to the program evaluation for selection of airport site. In order to make the entire decision-making process more rational and rationalization, the lattice-ordered decision theory is introduced combined the objective weight with subjective rights through comprehensive weight calculation.

\section{OVERVIEW OF LATTICE ORDER DECISION MAKING}

Lattice Order Decision Making for complex system to solve the preferential non-totally ordered, portrayed scheduling problem, decision-makers constitute a preference elements of different decision alternatives, lattice-ordered to reflect more realistically than the total order of preference structures of decision-makers, and thus for complex multi-element system merit comparison and selection problems, lattice-ordered decision is more scientific and reasonable compared to the total order decision-making. See Ref. [1].

\section{LATtice Order Decision MAKING MOdel FOR AIRPORT SITE SELECTION}

\section{A. Construction of Index System for Airport Site} Selection Scheme evaluation

As for alternative cities being prepared to build Airport, this paper started up to its own characteristics and layout 
of the integrated transport, and built Index System for Airport Site Selection Scheme evaluation reasonably. The following 3 points should be considered for Index selection: (1) combing National condition and Airport factor and reflect the nature of the problem as comprehensive as possible; (2) taking Index data's access and process of evaluation's operability into account; (3) . In order to facilitate follow-up discussions, set the number of evaluation schemes as ' $\mathrm{m}$ ' and the number of Evaluation Index as ' $n$ ', then the Index Evaluation Matrix for each Scheme is

$$
P=\frac{\mathrm{G}_{2}}{\mathrm{G}_{1}} \underset{\mathrm{G}_{1}}{\mathrm{G}_{\mathrm{m}}}\left[\begin{array}{cccc}
p_{11} & p_{12} & \cdots & p_{1 n} \\
p_{21} & p_{22} & \cdots & p_{2 n} \\
\cdots & \cdots & \cdots & \cdots \\
p_{m 1} & p_{m 2} & \cdots & p_{m n}
\end{array}\right]
$$

Where: $p_{i j}$ are the Evaluation value for Scheme $G_{i}$ relative to Index $D_{j}$.

\section{B. Make indexes being dimensionless}

As different index has different unit which is lack of common measure, and it is necessary to handle the index evaluation data for it's the positive index and reverse index, appropriate index and interval index respectively. The process can be seen from Ref. [1].

\section{Weight Determination}

The methods of weight calculation are mainly subjective judgment and objective analysis at home and abroad. The main disadvantage of subjective judgment method is over-rely on the experts' experience while the objective analysis defect to ignore the knowledge and experience of experts, and results by computing depart from the actual largely. In view of these shortcomings, the paper combine the above two methods effectively, and its process is to be elaborated as follow:

(a) Objective scatter weight calculation ${ }^{[1]}$

Take the objective weight vector for scatter of the indexes as $w^{*}=\left(w_{1}^{*}, w_{2}^{*}, \ldots . ., w_{n}^{*}\right)$, and $\sum_{j=1}^{n}\left(w_{j}^{*}\right)^{2}=1$

for $j$ th index of the $i$ th scheme and value for the same index of other schemes is calculated as follows. $\lambda_{i j}\left(w_{j}^{*}\right)=\sum_{k=1}^{m} w_{j}^{*}\left|p_{i j}-p_{k j}\right|$

Take $\lambda_{j}(a)$ as the sum of deviation for all scheme with the $j$ th index, it is calculated as follows.

$$
\lambda_{j}\left(w_{j}^{*}\right)=\sum_{i=1}^{m} \lambda_{i j}=\sum_{i=1}^{m} \sum_{k=1}^{m}{ }^{*} w_{j}\left|p_{i j}-p_{k j}\right|
$$

The weight is got by maximizing the sum of deviation, namely, the final weight of each index should result to the $\sum_{i=1}^{n} \lambda_{j}\left(w_{j}^{*}\right)$ objective programming.

$$
\left\{\begin{array}{l}
F\left(w_{j}^{*}\right)=\sum_{i=1}^{n} \lambda_{j}\left(w_{j}^{*}\right)=\sum_{j=1}^{n} \sum_{i=1}^{m} \sum_{k=1}^{m} w_{j}^{*}\left|p_{i j}-p_{k j}\right| \\
\text { st. } \sum_{j=1}^{n}\left(w_{j}^{*}\right)^{2}=1, \quad w_{j} \geq 0 \quad(j=1,2 \ldots m)
\end{array}\right.
$$

By solving this function, we get the objective weight vector $w^{s}=\left(w_{1}^{s}, w_{2}^{s}, \ldots . ., w_{n}^{s}\right)$ by normalization. The formula for normalization is as follows.

$$
w_{j}^{s}=\frac{w_{j}^{*}}{\sum_{j=1}^{n} w_{j}^{*}}=\frac{\sum_{i=1}^{m} \sum_{k=1}^{m} w_{j}^{*}\left|p_{i j}-p_{k j}\right|}{\sum_{j=1}^{n} \sum_{i=1}^{m} \sum_{k=1}^{m} w_{j}^{*}\left|p_{i j}-p_{k j}\right|}
$$

(b) Subjective weight calculation

Analytical Hierarchy Process (AHP) is applied for the process of expert's qualitative evaluation, related process method to AHP could be seen from literature [9]. The subjective weight vector we get is $w^{o}=\left(w_{1}^{o}, w_{2}^{o}, \ldots . ., w_{n}^{o}\right)$.

(c) Synthetic total weight

The total weight of a certain index should relate to both subjective weight and objective weight, thus, we define the total weight vector as $w=\left(w_{1}, w_{2}, \ldots . ., w_{m}\right)$, where

$$
w_{j}=\frac{w_{j}^{s} \cdot w_{j}^{o}}{\sum_{j=1}^{n} w_{j}^{s} \cdot w_{j}^{o}}
$$

\section{Decision matrix computing}

By defining an operator $d_{i j}=w_{j} \cdot p_{i j}^{\prime}$, where $p_{i j}^{\prime}$ is the dimensionless index value, the decision matrix can be written as follows. 


$$
D=\left[\begin{array}{cccc}
d_{11} & d_{12} & \ldots & d_{1 n} \\
d_{21} & d_{22} & \ldots & d_{2 n} \\
\ldots & \ldots & \ldots & \ldots \\
d_{m 1} & d_{m 2} & \ldots & d_{m n}
\end{array}\right]
$$

\section{E. Scheme Rank}

According to the lattice order theory, the positivenegative ideal solutions are

$$
\begin{aligned}
& M^{+}=\left(\max _{i=1}^{m} d_{i 1}, \max _{i=1}^{m} d_{i 2}, \ldots . ., \max _{i=1}^{m} d_{i n}\right) \\
& M^{-}=\left(\min _{i=1}^{m} d_{i 1}, \min _{i=1}^{m} d_{i 2}, \ldots . ., \min _{i=1}^{m} d_{i n}\right)
\end{aligned}
$$

The Euclid Distance between the two solutions is

$$
L=\sqrt{\sum_{j=1}^{n}\left(\max _{i=1}^{m} d_{i j}-\min _{i=1}^{m} d_{i j}\right)^{2}}
$$

The Euclid Distance between the $\mathrm{i}^{\text {th }}$ scheme and the positive-negative ideal solutions are

$$
\begin{gathered}
L_{i}^{+}=\sqrt{\sum_{j=1}^{n}\left(\max _{k=1}^{m} d_{k j}-d_{i j}\right)^{2}} \\
L_{i}^{-}=\sqrt{\sum_{j=1}^{n}\left(d_{i j}-\min _{k=1}^{m} d_{k j}\right)^{2}}
\end{gathered}
$$

Taken the comprehensive difference degree of the $\mathrm{i}^{\text {th }}$ scheme as

$$
L_{i}=q \frac{L_{i}^{-}}{L}+(1-q) \frac{L_{i}^{+}}{L}
$$

Where $q$ is the optimistic coefficient $(0<\mathrm{q}<1)$, given by experts subjectively according to the $\mathrm{i}^{\text {th }}$ Scheme closeness $L_{i}((i=1,2 \ldots . . m))$, the lattice order of alternative schemes is achieved.

\section{ExAmple Of NeW Airport Site Selection SCHEME EVALUATION}

\section{A. Construction of New Airport Evaluation System}

As ground transportation level in Chengdu and Sichuan is lagging behind relative to the eastern and central regions, and Shuangliu Airport of Chengdu as a regional hub for supply approximate saturated, the new airport has gradually been put on the agenda. This paper takes the New Airport Site Selection of Chengdu for example, and the alternative addresses are Jianyang, Renshou and Chengdu Jintang County, which is tagged as Scheme (1)(2) (3) (Figure1). The airport site evaluation index system is built on its actual situation and the optimization of an integrated transport system, as shown in Figure2. The evaluation method of "Urban openness" could be seen from Ref. [7], and "closeness of comunication with the central city" refers to economic and trade exchanges and space transport links' integrated handling, and evaluation method on "surrounding land's development value " could be seen from Ref. [10 ].

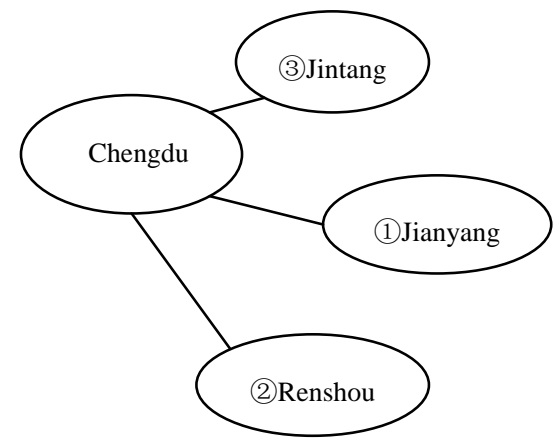

Figure 1. Geographic distribution

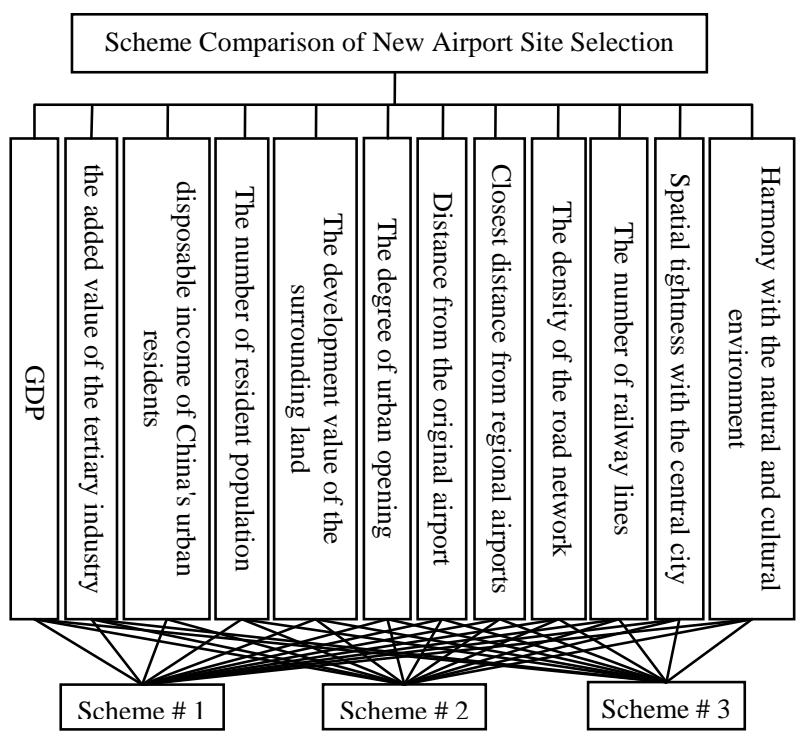

Figure 2. Comparison and Selection System of New Airport Site Scheme

\section{B. Make indexes being dimensionless}

The indexes of site selection scheme evaluation are classified as Positive index set, Reverse index set and appropriate index set. The Positive index set includes elements of $\operatorname{GDP}\left(\mathrm{D}_{1}\right)$, the added value of the tertiary industry $\left(\mathrm{D}_{2}\right)$, disposable income of Chinese urban residents $\left(\mathrm{D}_{3}\right)$, The number of resident population $\left(\mathrm{D}_{4}\right)$, the development value of the surrounding land $\left(\mathrm{D}_{5}\right)$, the degree of urban opening $\left(\mathrm{D}_{6}\right)$, the density of the road network $\left(D_{9}\right)$, the density of the railway network $\left(D_{10}\right)$, spatial tightness with the central city $\left(\mathrm{D}_{11}\right)$ and harmony 
with the natural and cultural environment $\left(\mathrm{D}_{12}\right)$. The Appropriate index set includes Distance from the original airport $\left(D_{7}\right)$ and Closest distance from regional airports $\left(D_{8}\right)$. The result of indexes being dimensionless are shown in Table I.

\section{Index weight definition}

The subjective weight is defined according to the related data of Ref. [1], while the objective weight and integrated weight are calculated by the (5), (6) with related index data of table1. Evaluation system's total weight is shown in table II.

\section{Decision matrix computing}

use (7) and data in table I and II, calculate through MATLAB, and obtain the system decision matrix, as shown in table III.

\section{E. Integrated Difference calculation and the order of Scheme}

Use table III. and Equation (8) and (9) to obtain the solution, and then use (10) to obtain the Euclidean distance 0.264213928 . Use (11) and (12) to obtain the Euclidean distance between the solution and Ideal Solution. Assume the optimistic coefficient $\mathrm{q}$ is 0.5 , use (13) to calculate the comprehensive differences of different schemes. The results are shown in table IV.

Based on integrated difference value, the order for Network Scheme from good to bad is in the order of Scheme 1, Scheme 2 and Scheme 3. And there are 7 indexes of Scheme 1 reached to its optimal value. Then it can be drawn that Scheme 4 has the best effect, and the results is consistent with the city's network planning project options Sort results. This indicates the comprehensive difference values of the schemes using the method of lattice order Decision Making could solve the problem of less obvious gap between the alternative schemes.

\section{CONCLUSIONS}

This paper applied the method of lattice order Decision Making for airport site scheme evaluation, comparison and selection under integrated transport system, and combined with example, evaluation methods and processes was taken for useful attempt. Based on the calculation of schemes' integrated difference, pros and cons of sorting for the schemes are achieved. Synthesis method was applied to calculate consolidated weight for each index and to achieve the subjective and objective weight convergence and unified effectively. Furthermore, the rationality of the method was proved with comparison of actual project evaluation.

\section{REFERENCES}

[1] Liu Yuzeng, and Qian Bingyi. "Multi-objective lattice-order decision-making method of scheme selection for rail transit network," Journal of Traffic and Transportation Engineering, Vol.11, Issue 5, Oct. 2011, pp.77-79.

[2] Guo Qiang, and Guo Chunxiang, Guo Yaohuang. "Method of group decision making based on the distance of lattice order preferences," Systems Engineering and Electronics, Vol32, Issue 2, 2010, pp.298-302.

[3] Skinner J R E. "Airport choice: an empirical study," Transportation Engineering Journal, Vol. 102, Issue 4, 1976, pp. 871-883.

[4] Harvey G. "Study of airport access mode choice," Journal of Transportation Engineering, Vol.112, Issue5, 1986, pp. 525-545. http://dx.doi.org/10.1061/(ASCE)0733-947X(1986)112:5(525)

[5] Monteiro A B F, and Hansen M. "Improvements to airport ground access and behavior of multiple airport system:BART extension to san francisco international airport," Transportation Research Record, 1999, pp. 38-47.

[6] Erwin A. Blackstone and Andrew J. Buck, "Simon Hakim. Determinants of Airport Choice in a Multi-airport Region.” Department of Economics Temple University, Oct. 2003.

[7] Wang Faming. "The Framework of the Evaluation Index System of Opening up: Take Hangzhou as Example,” Reform, Sep. 2008.

[8] Yang Xiuyun, and YaoShujie. "The Determinants of Airport Industry Development in China: Empirical Analysis Based on Augmented Production Function," Modern Economic Science, Issue 1, 2009.

[9] LI Junfang, and WU Xiaoping. "Synthetic evaluation for urban rail transit line network planning scheme based on AHP fuzzy method," Journal of Wuhan University of Technology: Transportation Science \& Engineering, Vol. 31, Issue 2, 2007, pp.206-208.

[10] "Based on the analysis of development intensity index system of construction land value," Planning innovation: proceedings of 2010 annual meeting of Chinese urban planning, Shanghai, China, 2010 .

\section{AUTHORS}

Suxia Zhao is with School of Transportation and Logistics, Southwest Jiaotong University, and Sichuan Vocational and Technical College of Communications, China (E-mail: suzsx@sina.com)

Peihong Sun is with Twenty First Century Aerospace Technology Co.,Ltd. Beijing, China (E-mail: 19615876@qq.com)

This article is an extended and modified version of a paper presented at the International Conference on Mechanical Engineering, Automation and Material Science (MEAMS2012), held 22-23 December 2012, Wuhan, China. Received 25 April 2013. Published as resubmitted by the authors 01 May 2013.

TABLE I.

INDEX VALUE OF NEW AIRPORT SITE SELECTION SCHEME

\begin{tabular}{|c|c|c|c|c|c|c|c|c|c|c|c|c|}
\hline \multirow{2}{*}{$\begin{array}{l}\text { Site Selection } \\
\text { Scheme }\end{array}$} & \multicolumn{12}{|c|}{ Index dimensionless of Site Selection Scheme evaluation } \\
\hline & $\mathbf{D}_{1}$ & $\mathbf{D}_{2}$ & $\mathbf{D}_{3}$ & $\mathbf{D}_{4}$ & $\mathbf{D}_{5}$ & $\mathbf{D}_{6}$ & $\mathbf{D}_{7}$ & $\mathbf{D}_{8}$ & $\mathbf{D}_{9}$ & $\mathbf{D}_{10}$ & $\mathbf{D}_{11}$ & $\mathbf{D}_{12}$ \\
\hline $\mathrm{G}_{1}$ & 0.526 & 0.309 & 0.964 & 0.467 & 0.875 & 0.889 & 0.125 & 0.44 & 0.909 & 0.660 & 0.852 & 0.820 \\
\hline $\mathbf{G}_{2}$ & 0.448 & 0.336 & 0.833 & 0.540 & 0.75 & 0.667 & 0.75 & 0 & 0.455 & 0.440 & 0.905 & 0.726 \\
\hline $\mathbf{G}_{3}$ & 0.328 & 0.298 & 0.899 & 0.287 & 0.875 & 0.778 & 0.8 & 0.53 & 0.455 & 0.448 & 0.804 & 0.725 \\
\hline
\end{tabular}

Note: The data without dimensionless comes from Sichuan province's statistical yearbook and the Chengdu's statistical yearbook. 
TABLE II.

INDEX WEIGHT FOR NEW AIRPORT SITE SELECITON SCHEME EVALUATION

\begin{tabular}{|c|c|c|c|c|c|c|c|c|c|c|c|c|}
\hline \multirow{2}{*}{ Weight Type } & \multicolumn{10}{|c|}{ Index weight for site selection scheme evaluation } \\
\cline { 2 - 13 } & $\mathbf{D}_{\mathbf{1}}$ & $\mathbf{D}_{\mathbf{2}}$ & $\mathbf{D}_{\mathbf{3}}$ & $\mathbf{D}_{\mathbf{4}}$ & $\mathbf{D}_{\mathbf{5}}$ & $\mathbf{D}_{\mathbf{6}}$ & $\mathbf{D}_{\mathbf{7}}$ & $\mathbf{D}_{\mathbf{8}}$ & $\mathbf{D}_{\mathbf{9}}$ & $\mathbf{D}_{\mathbf{1 0}}$ & $\mathbf{D}_{\mathbf{1 1}}$ & $\mathbf{D}_{\mathbf{1 2}}$ \\
\hline $\mathbf{w}^{\mathbf{0}}$ & 0.039 & 0.067 & 0.110 & 0.030 & 0.041 & 0.175 & 0.141 & 0.048 & 0.065 & 0.023 & 0.220 & 0.041 \\
& & & & & & & & & & & & \\
\hline $\mathbf{w}^{\mathbf{s}}$ & 0.051 & 0.011 & 0.046 & 0.084 & 0.032 & 0.087 & 0.234 & 0.186 & 0.142 & 0.069 & 0.041 & 0.016 \\
\hline $\mathbf{w}$ & 0.023 & 0.008 & 0.057 & 0.027 & 0.015 & 0.17 & 0.371 & 0.1 & 0.104 & 0.017 & 0.101 & 0.007 \\
\hline
\end{tabular}

TABLE III.

DECISION MATRIX OF NEW AIRPORT SITE SELECTION SCHEME

\begin{tabular}{|c|c|c|c|c|c|c|c|c|c|c|c|c|}
\hline \multirow{2}{*}{$\begin{array}{c}\text { Site Selection } \\
\text { Scheme }\end{array}$} & \multicolumn{10}{|c|}{ Decision index value of Site Selection Scheme } \\
\cline { 2 - 14 } & $\mathbf{D}_{\mathbf{1}}$ & $\mathbf{D}_{\mathbf{2}}$ & $\mathbf{D}_{\mathbf{3}}$ & $\mathbf{D}_{\mathbf{4}}$ & $\mathbf{D}_{\mathbf{5}}$ & $\mathbf{D}_{\mathbf{6}}$ & $\mathbf{D}_{\mathbf{7}}$ & $\mathbf{D}_{\mathbf{8}}$ & $\mathbf{D}_{\mathbf{9}}$ & $\mathbf{D}_{\mathbf{1 0}}$ & $\mathbf{D}_{\mathbf{1 1}}$ & $\mathbf{D}_{\mathbf{1 2}}$ \\
\hline $\mathbf{G}_{\mathbf{1}}$ & 0.012 & 0.002 & 0.055 & 0.013 & 0.013 & 0.151 & 0.046 & 0.044 & 0.095 & 0.011 & 0.086 & 0.006 \\
\hline $\mathbf{G}_{\mathbf{2}}$ & 0.010 & 0.003 & 0.047 & 0.015 & 0.011 & 0.113 & 0.278 & 0.000 & 0.047 & 0.007 & 0.091 & 0.005 \\
\hline $\mathbf{G}_{\mathbf{3}}$ & 0.008 & 0.002 & 0.051 & 0.008 & 0.013 & 0.132 & 0.297 & 0.053 & 0.047 & 0.008 & 0.081 & 0.005 \\
\hline
\end{tabular}

TABLE IV

OVERALL CALCULATIONS RESULT

\begin{tabular}{|c|c|c|c|c|c|c|}
\hline \multirow{2}{*}{ Parameter } & \multicolumn{2}{|c|}{ Scheme 1 } & \multicolumn{2}{c|}{ Scheme 2 } & \multicolumn{2}{c|}{ Scheme 3 } \\
\cline { 2 - 7 } & $\begin{array}{c}\text { Positive Ideal } \\
\text { Solution }\end{array}$ & $\begin{array}{c}\text { Negative Ideal } \\
\text { Solution }\end{array}$ & $\begin{array}{c}\text { Positive Ideal } \\
\text { Solution }\end{array}$ & $\begin{array}{c}\text { Negative Ideal } \\
\text { Solution }\end{array}$ & $\begin{array}{c}\text { Positive Ideal } \\
\text { Solution }\end{array}$ & $\begin{array}{c}\text { Negative Ideal } \\
\text { Solution }\end{array}$ \\
\hline Euclidean Distance & 0.251221 & 0.076387 & 0.083708 & 0.232332 & 0.053451 & 0.257327 \\
\hline $\begin{array}{c}\text { Comprehensive } \\
\text { difference value }\end{array}$ & \multicolumn{2}{|c|}{0.619968} & \multicolumn{2}{|c|}{0.598075} & \multicolumn{2}{|c}{0.588117} \\
\hline
\end{tabular}

